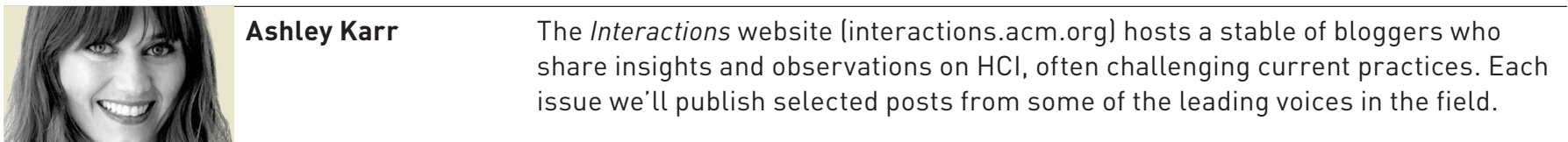

\title{
UX Research vs. UX Design
}

I f you get an opportunity to have a conversation with Skot Carruth, take it. He is a UX professional and principle at philosophie, a UX and product consulting firm. In addition, he is a fellow UCLA graduate, a smart man, and an allaround good person. Happily, we both stumbled upon the same phenomenon: There exists in industry a general lack of clarity and understanding regarding the role of a UX professional. On the one hand, this is unfortunate. We want everyone to know, love, and understand our chosen profession. On the other hand, this is very fortunate. It means, to paraphrase Don Norman, we are leaders in an emerging field and we have the opportunity to spread the word.

We enjoyed ourselves as we kicked around the questions:

- Is UX a noun or verb?

- Is UX a role you play or a process you champion?

-Where does the work of a UX professional begin and end?

-Where is the intersection of time spent and quality derived in the UX research and design process?

We did not generate sensational answers to all of these questions; however, we did celebrate when we settled on the idea that $U X$ is a continuum - between a role and a process. On the far left, we find UX research, and on the far right, we find UX/UI design. Skot drew a very nice picture of our hypothetical continuum (Figure 1). Here's what else we uncovered during our conversation one balmy Los Angeles afternoon.

Defining research. To research something is to investigate it systematically. We do this in order to reach new conclusions, establish new facts, and learn as much about the truth as possible. Research also

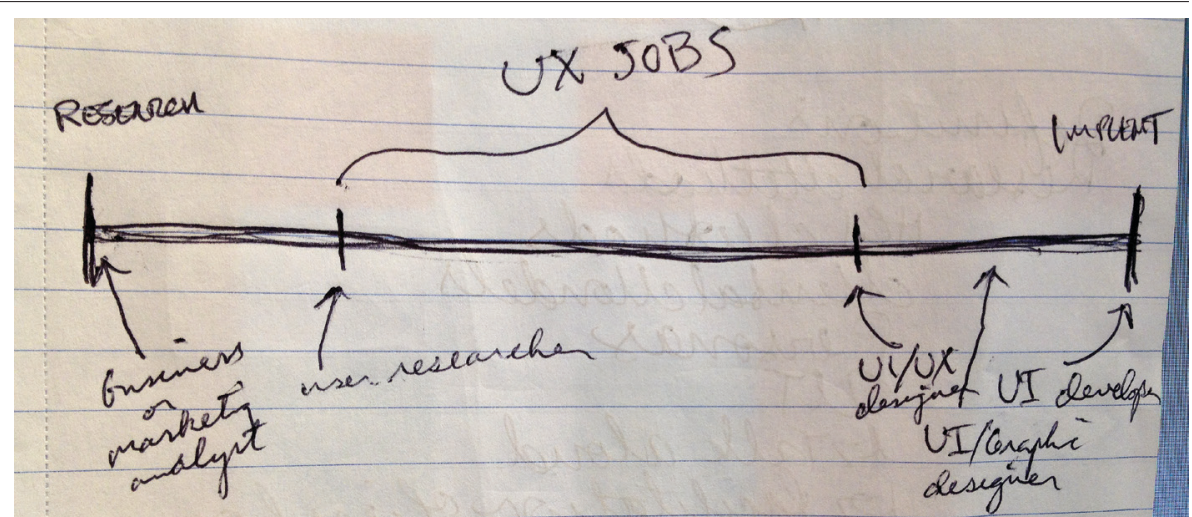

Figure 1. The UX research and design continuum, by Skot Carruth.

gives us a chance to find problems that we can potentially fix. We research to understand the world.

Defining design. To design something is to create the form and function of an object, system, or interaction. We do this in order to make our experience here on earth (or in space) better, safer, healthier, more comfortable, more fun - and we can create solutions to the problems we found during our research. We design to change the world.

Contemplating the UXjob description continuum. As mentioned, Skot and I decided that UX was a continuum that begins with UX research and ends with UX/UI design. This may explain why there is some confusion regarding what educational background a UX professional should have, what role they should play on a design team, and what part of the design process they should "own.” (I disagree with the concept that someone can actually own a part of the design process, but that is another discussion entirely.) UX professionals with backgrounds in the social or behavioral sciences and who are very adept at gathering and analyzing data are perfectly primed to work as
UX researchers. Graphic designers, industrial designers, and engineers who are adept at creating tangible products would then be perfectly primed to work as UX designers.

These are not hard and fast rules. These are the result of Skot's and my attempt to define and organize a very complex, multidisciplinary field. Skot adds, "I think one unified way to define UX is that it is a perspective-a lens through which you can view your product, service, or organization. It is the lens through which your users view you, as well. In my opinion, anyone who can use this perspective is practicing UX."

We are curious to hear what other UX professionals think. We would love to hear how you bring clarity about your role and responsibilities to your design team. Until next time, please enjoy the experience.

\footnotetext{
(4) Ashley Karr specializes in $\mathrm{HCl}, \mathrm{UX}$ research, and design. She teaches at General Assembly and runs the Design Thinking Boutique, where she creates products to help design professionals stay inspired and satisfied in their craft. http://interactions.acm.org/blog/ author/8592/Ashley\%20Karr

$\rightarrow$ ashleydashleykarr.com
} 